\title{
Analisis Kelayakan Usaha Kerajinan Anyaman Kipas Rotan Di Desa Sungai Limas Kecamatan Haur Gading Kabupaten Hulu Sungai Utara
}

\section{(The Feasibility Analysis of Rattan Fan Industry in Sungai Limas Village Haur Gading Distric Hulu Sungai Utara Regency)}

\author{
Azwar Saihani $^{1)}$ \& Mislawati \\ Program Studi Agribisnis, Sekolah Tinggi Ilmu Pertanian Amuntai \\ 1)Azwar.saihani63@yahoo.com
}

\begin{abstract}
ABSTRAK
Rotan sebagai bahan baku dari industri mebel dan produk bahan rotan. Produk rotan ini banyak dilakukan di Kabupaten H.S.U. Penelitian ini memiliki tujuan (i) untuk mengetahui berapa biaya yang kita butuhkan dan berapa yang akan diterima. (ii) untuk mengetahui kelayakan pengrajin rotan menggunakan bahan anyaman rotan. (iii) untuk mengetahui masalah yang muncul oleh pengrajin bahan anyaman kipas rotan di Desa Sungai Limas. Penelitian ini telah dilakukan di Desa Sungai Limas Kecamatan Haur Gading Kabupaten Hulu Sungai Utara Kalimantan Selatan. Penelitian ini dilaksanakan pada bulan April - Juni 2010. Hasil penelitian adalah biaya tetap Rp. 15.535,49, - per produksi, biaya variabel Rp. 91.911,32, - untuk sekali produksi, pendapatan Rp. 152.452,83, - untuk sekali produksi dan RCR 1,42 .
\end{abstract}

Kata kunci: Industri kipas rotan, rasio biaya pendapatan, analisis feseabilitas.

\section{ABSTRACT}

Rattan as trunk rattan from for rattan mebel industries and rattan material product. This rattan product is much done in H.S.U regency. This research has the goals (i) To know how much fee that we need and how much will get the accepted. (ii) To know the properness of rattan the industrious of rattan plaited material. (iii) To know the appeared problem by the industrious of rattan fan plaited material craftsman in Sungai Limas Village. This research have been done in Sungai Limas Village Haur Gading Distric Hulu Sungai Utara Regency South Kalimantan. This research strated in April - June 2010. The result of the research were fixed cost $R p$. 15.535,49,- per production, variable cost $R p$. 91.911,32,- for once production, revenue $R p$. 152.452,83,- for once production and $R C R$ 1,42.

Keywords : Rattan fan industry, revenue cost ratio, feseability analysis.

\section{PENDAHULUAN}

Pengembangan sektor industri berkaitan dengan penyerapan tenaga kerja. Dihubungkan dengan pem-bangunan sektor pertanian, sektor industri terutama industri pengolahan hasil pertanian memegang peranan penting di negara kita. Perlunya pengembangan sektor industri pengo-lahan hasil-hasil pertanian adalah untuk memberi nilai tambah produk pertanian. Hal ini akan menambah manfaat yang lebih luas, baik dalam hal memenuhi kebutuhan masyarakat maupun bagi pengusaha industri tersebut (Mubyarto, 1997). Kerajinan merupakan salah satu peluang usaha bagi masyarakat. Hal ini sangat penting dan seiring dengan perubahan diberbagai bidang dalam masyarakat pedesaan yang disebabkan oleh perubahan jaman, pertumbuhan penduduk, pengu-asaan tanah pertanian yang semakin kecil, dan perubahan pendapatan dalam kehidupan masyarakat secara keseluruhan (Setiawan, 2002).

Jenis komoditi industri kecil di Kabupaten Hulu Sungai Utara dengan jumlah produksi tertinggi yaitu sebanyak 750.000 buah adalah komoditas anyaman rotan (Dinas Perindustrian dan Koperasi Kabupaten HSU, 2009). Perkembangan produksi anyaman rotan di Kabupaten Hulu Sungai Utara dari tahun ke tahun cukup meningkat dari sebanyak 660 buah, pada tahun 2005 menjadi 25.100 buah pada tahun 2009 (Badan Pusat Statistik Kab. HSU, 2010). 
Rawa Sains: Jurnal Sains STIPER Amuntai, Desember 2011, 1(1), 18-23.

Perkembangan jumlah pengrajin anyaman rotan di Kecamatan Haur Gading tahun 2005 sebanyak 15 orang, menjadi 48 orang pada tahun 2009. Perkembangan produksi anyaman rotan di Desa Sungai Limas Kecamatan Haur Gading khususnya jenis komoditi anyaman kipas rotan sebamyak 2.880 buah pada tahun 2006 menjadi sebanyak 3840 buah tahun 2009 (Tim Penyusun, 2009).

Sebagai suatu industri rumah tangga, maka pengrajin akipas anyaman rotan perlu mengetahui berapa biaya yang dikeluarkan dan berapa penerimaan yang diperoleh pengrajin anyaman rotan di Desa Sungai Limas selama satu periode, sehingga dapat diketahui apakah usaha kerajinan anyaman kipas rotan ini layak atau tidak untuk diusahakan. Sehingga tujuan penelitian yaitu menhetahui : (i) berapa besar biaya yang dikeluarkan serta berapa besar penerimaan yang diperoleh.serta (ii) kelayakan usaha kerajinan anyaman kipas rotan di Desa Sungai Limas Kecamatan Haur Gading Kabupaten Hulu Sungai Utara.

\section{METODE PENELITIAN}

\section{Tempat dan Waktu Penelitian}

Penelitian dilaksanakan di Desa Sungai Limas Kecamatan Haur Gading Kabupaten Hulu Sungai Utara Propinsi kalimatan selatan. Penelitian ini dilaksanakan pada bulan April sampai Juni 2010.

\section{Jenis dan Sumber Data}

Penelitian ini menggunakan data primer dan data sekunder. Metode pengumpulan data menggunakan metode sensus, dimana pengrajin anyaman kipas rotan sebagai responden. Dengan jumlah responden 53 pengrajin anyaman kipas rotan.

\section{Analisa Data}

Biaya. Biaya dalam usaha kerajinan anyaman kipas rotan meliputi biaya tetap dan biaya variabel. Komponen biaya tetap dalam usaha kerajinan anyaman kipas rotan ini yaitu penyusutan pemeliharaan peralatan, biaya tenaga kerja dalam keluarga (TKDK) dan biaya bunga modal. Biaya variabel berupa harga bahan baku seperti rotan, tali plastik dan pewarna. Perhitungan dalam satu kali proses produksi yakni 1 (satu) minggu.

$$
\begin{aligned}
& \text { TC }=\mathbf{F C}+\mathbf{V C} \\
& \text { Dimana: } \\
& \text { TC }=\text { Total biaya }(\mathrm{Rp}) \\
& \mathrm{FC}=\text { Biaya tetap }(\mathrm{Rp}) \\
& \mathrm{VC}=\text { Biaya variabel }(\mathrm{Rp})
\end{aligned}
$$

Biaya Penyusutan. Untuk menghitung biaya penyusutan barang selama satu periode produksi

Dimana:

$$
\mathbf{P b m}=\frac{\mathrm{Na} \cdot \sum \mathbf{Q}}{\mathrm{UE}}
$$

$\mathrm{Pbm}=$ Besarnya nilai penyusutan barang modal tetap yang di pergunakan untuk usaha tertentu selama masa periode (minggu).

$\mathrm{Na}=$ Besarnya nilai awal barang modal tetap yang sama dengan harga pengadaan atau harga pembelian $(\mathrm{Rp})$

$\Sigma \mathrm{Q}=$ Jumlah unit barang yang digunakan selama masa periode.

UE = Usia ekonomis barang (tahun)

\section{Penerimaan}

Penerimaan total merupakan jumlah dari hasil perkalian antara total output dengan harga persatuan output. Secara matematis total penerimaan dirumuskan sebagai berikut:

$$
\mathbf{T R}=\mathbf{Y} \text {. Py }
$$

Dimana:

$$
\begin{aligned}
\mathrm{TR} & =\text { Total penerimaan }(\mathrm{Rp}) \\
\mathrm{Y} & =\text { Jumlah output/hasil produksi } \\
\text { (ekor) } & \text { Py }=\text { Harga output (Rp/ekor) }
\end{aligned}
$$

\section{Kelayakan Usaha}

Tujuan kedua yaitu mengetahui kelayakan usaha kerajinan anyaman kipas rotan dilakukan analisis perbandingan antara penerimaan dan biaya, dapat dirumuskan sebagai berikut:

$$
\begin{aligned}
& \mathbf{R C R}=\mathbf{T R} / \mathbf{T C} \\
& \mathrm{TR}=\mathrm{Y} . \mathrm{Py} \\
& \mathrm{TC}=\mathrm{FC}+\mathrm{VC} \\
& \mathrm{RCR}=\{(\mathrm{Y} . \mathrm{Py}) /(\mathrm{FC}+\mathrm{VC})\}
\end{aligned}
$$


Secara teoritis dengan rasio $\mathrm{RCR}=1$ artinya tidak untung dan tidak pula rugi. RCR > 1 bila suatu usahatani dikatakan menguntungkan. Atau sebaliknya RCR $<1$ maka usahatani tersebut rugi.

\section{HASIL DAN PEMBAHASAN}

\section{Biaya Tetap}

Pembiayaan kerajinan anyaman kipas rotan di tempat penelitian ini terdiri dari biaya tetap dan biaya variabel. Biaya tetap adalah biaya yang harus dikeluarkan, akan tetapi besar kecilnya tidak dipengaruhi oleh tingkat produksi yang dicapai. Dalam kerajinan anyaman kipas rotan komponen biaya tetap terdiri dari biaya penyusutan alat, biaya tenaga kerja dalam keluarga (TKDK) dan biaya bunga modal.

\section{Biaya Penyusutan}

Biaya alat dan perlengkapan yang tidak habis dipakai dalam satu kali proses produksi diperhitungkan atas nilai penyusutan dengan besarnya nilai pembelian harga awal barang di kali jumlah barang di bagi umur ekonomis barang tersebut. Total biaya penyusutan seluruhnya adalah sebesar Rp. 1.998,83,- per satu kali produksi (satu minggu) 2010. Untuk lebih jelasnya dapat dilihat pada $\quad$ Tabel

Tabel 1. Biaya penyusutan peralatan per satu kali produksi pada kerajinan anyaman kipas rotan tahun 2010.

\begin{tabular}{|c|c|c|}
\hline No & Jenis Alat dan Perlengkapan & Biaya Penyusutan (Rp) \\
\hline 1. & Rautan / Jangatan & 625 \\
\hline 2. & Pisau & 365,57 \\
\hline 3. & Gunting & 365,57 \\
\hline 4. & Palu & 520,83 \\
\hline 5. & Jarum & 121,86 \\
\hline & Jumlah & $1.998,83$ \\
\hline
\end{tabular}

Biaya Tenaga Kerja Dalam Keluarga (TKDK)

Biaya TKDK dalam menger-jakan kerajinan anyaman kipas rotan dari penganyaman sampai pembingkaian anyaman kipas rotan adalah Rp. 13.301,88,per satu kali produksi. Upah yang digunakan dihitung sesuai dengan hasil yang diperoleh yaitu Rp. 2.500,- per kodi pada satu kali produksi usaha (Tabel 2.).

Tabel 2. Biaya TKDK per satu kali produksi pada kerajinan anyaman kipas rotan tahun 2010

\begin{tabular}{ccc}
\hline No & Jenis Pekerjaan & Biaya TKDK \\
\hline 1. & Penganyaman & $6.650,94$ \\
2. & Pembingkaian & $6.650,94$ \\
\hline \multicolumn{2}{c}{ Jumlah } & $13.301,88$ \\
\hline
\end{tabular}

Biaya TKDK meliputi biaya penganyaman dan biaya pembingkaian sebesar Rp. 6.650,94,- yang didapat dari hasil rata - rata biaya TKDK dari 53 pengrajin responden, dengan upah tenaga

\section{Biaya Bunga Modal Sendiri}

Faktor produksi modal kerja yang dimaksud adalah seluruh biaya yang dikeluarkan untuk pengadaan sarana produksi seperti biaya rotan, biaya tali kerja untuk penganyaman dan pembingkaian masing-masing Rp. 2.500,- dikali dengan hasil masing-asing responden selama satu kali produksi.

plastik, biaya pewarna, biaya penyusutan alat dan perlengkapan. Biaya bunga modal sendiri diperhitungkan ber-dasarkan tingkat suku bunga untuk Usaha Kecil dan 
Rawa Sains: Jurnal Sains STIPER Amuntai, Desember 2011, 1(1), 18-23.

Menengah (UKM) pada Bank Rakyat Indonesia (BRI) sebesar $12 \%$ per tahun, 1 $\%$ per bulan atau $0,25 \%$ per minggu. Biaya bunga modal sendiri dimasukkan kedalam biaya tetap kerena didalam usaha kerajinan ini terdapat modal kerja yang dikeluarkan dalam proses produksi yang mana besar kecilnya biaya yang dikeluarkan tidak tergantung pada volume produksi yang dihasilkan. Biaya bunga modal sendiri yang dikeluarkan pengrajin responden adalah $\mathrm{Rp}$. 234,78 per satu kali produksi pada tahun 2010, yang didapat dari hasil perkalian antara modal sendiri dengan suku bunga sebesar $0,25 \%$ per satu kali produksi.

Tabel 3. Biaya tetap per satu kali produksi pada kerajinan anyaman kipas rotan tahun 2010

\begin{tabular}{cccc}
\hline No & Biaya Tetap & Jumlah Biaya (Rp) & Persentase $(\%)$ \\
\hline 1. & Biaya penyusutan alat & $1.998,83$ & 12,87 \\
2. & Biaya TKDK & $13.301,88$ & 85,62 \\
3. & Biaya bunga modal & 234,78 & 1,51 \\
\hline & Jumlah & $15.535,49$ & 100 \\
\hline
\end{tabular}

Total biaya tetap pada kerajinan anyaman kipas rotan per satu kali produksi pada tahun 2010 yaitu sebesar Rp. 15.535,49,-. (Tabel 3.). Biaya tetap terbesar adalah biaya tenaga kerja dalam keluarga (TKDK) yaitu sebesar Rp. 13.301,88,- per satu kali produksi dengan persentase $85,62 \%$, sedangkan biaya terkecil adalah biaya bunga modal yaitu sebesar Rp. 234,78,- per satu kali produksi dengan persentase $1,51 \%$.

\section{Biaya Variabel}

Biaya variabel adalah biaya yang harus dikeluarkan pada suatu usaha yang besar kecilnya tergantung pada jumlah produksi yang dicapai. Komponen biaya variabel pada usaha kerajinan anyaman kipas rotan yaitu biaya sarana produksi seperti rotan, tali plastik dan pewarna. Rincian biaya variabel rata-rata yang dikeluarkan pada kerajinan anyman kipas roatan dapat dilihat pada Tabel 4.

Tabel 4. Rata-rata biaya variabel per satu kali produksi pada kerajinan anyaman kipas rotan tahun 2010

\begin{tabular}{cccc}
\hline No & Biaya Variabel & Jumlah Biaya $(\mathrm{Rp})$ & Persentase $(\%)$ \\
\hline 1. & Biaya rotan & 82.001 .89 & 89,22 \\
2. & Biaya tali plastik & $3.811,32$ & 4,15 \\
3. & Biaya pewarna & $6.098,11$ & 6,63 \\
\hline & Jumlah & $91.911,32$ & 100
\end{tabular}

Sumber: Pengolahan Data Primer Pada Kerajinan Anyaman Kipas Rotan di Desa Sungai Limas 2010

Variabel terbesar yang dikeluarkan pengrajin responden adalah pada biaya rotan yaitu sebesar Rp. 82.001,89,- per satu kali produksi dengan persentase $89,22 \%$. Sedangkan biaya variabel terkecil adalah biaya tali plastik yaitu sebesar $\mathrm{Rp}$.
3.811,32,- per satu kali produksi dengan persentase 4,15 .

\section{Biaya Total}

Biaya total dari kerajinan anyaman kipas rotan adalah penjumlahan dari total biaya tetap dan biaya total variabel.

Tabel 5. Rata-rata biaya total per satu kali produksi pada kerajinan anyaman kipas rotan tahun 2010

\begin{tabular}{lll}
\hline No & Uraian Biaya & Jumlah Biaya $(\mathrm{Rp})$
\end{tabular}


Azwar Saihani \& Mislawati, Analisis kelayakan usaha kerajinan...

\begin{tabular}{|c|c|c|}
\hline 1. Biaya tetap & $15.535,49$ & 14,46 \\
\hline 2. Biaya Variabel & $91.911,32$ & 85,54 \\
\hline Jumlah & $107.446,81$ & 100 \\
\hline
\end{tabular}

Komponen biaya total terbesar adalah biaya variabel sebesar $\mathrm{Rp}$. 91.911,32,- dengan persentase 85,54 \%, yang didapat dari penambahan antara biaya rotan sebesar Rp. 82.001,89, biaya tali plastik sebesar Rp. 3.811,32,-, dan biaya pewarna sebesar Rp. 6.098,11,-. Sedangkan untuk biaya tetap sebesar Rp. 15. 535,49,dengan persentase $14,46 \%$, yang didapat dari penambahan antara biaya penyusutan alat sebesar Rp. 1.998,83,-, biaya TKDK sebesar Rp. 13.301,88,- dan biaya bunga modal sebesar Rp. 234,78,- (Tabel 5.).

\section{Penerimaan}

Penerimaan kerajinan anyaman kipas rotan ini adalah perkalian antara hasil produksi yang diperoleh dengan harga jual yang berlaku tingkat pengrajin (Tabel 6.). Rata - rata jumlah produksi adalah 7,62 kodi per satu kali produksi dengan rata - rata harga jual sebesar Rp. 20.000,- per kodi. Dari hasil perhitungan dapat diperoleh ratarata penerimaan yang diterima pengrajin anyaman kipas rotan pada satu kali produksi adalah Rp. 152.452,83,-.

Tabel 6 .Rata - Rata Penerimaan Per satu Kali Produksi Pada Kerajinan Anyaman Kipas Rotan Tahun 2010

\begin{tabular}{cccc}
\hline No & Jumlah Produksi & Harga per kodi (Rp) & Jumlah Penerimaan (Rp) \\
\hline 1. & 7,62 & 20.000 & $152.452,83$ \\
\hline
\end{tabular}

\section{Analisis Kelayakan}

RCR yang diperoleh dari kerajinan anyaman kipas rotan ini adalah besarnya total penerimaan di bagi dengan besarnya biaya total (Tabel 7.). Hasil perhitungan menunjukkan rata-rata RCR dari kerajinan anyaman kipas rotan yang diterima 53 pengrajin responden adalah $\mathrm{Rp}$. 1,42,artinya kerajinan anyaman kipas rotan ini layak untuk di usahakan, walaupun keutungan yang diperoleh sebenarnya sedikit.

Tabel 7. Rata-rata RCR per satu kali produksi pada kerajinan anyaman kipas rotan tahun 2010

\begin{tabular}{ccc}
\hline No & Total Penerimaan : Total Biaya & RCR \\
\hline 1. & $152.452,83: 107.446,81$ & 1,42 \\
\hline
\end{tabular}

Karena dari hasil kerajinan ini cukup bagi ibu - ibu rumah tangga di Desa Sungai Limas sebagai tambahan pendapatan keluarga untuk meringankan suami mereka dalam memenuhi kebutuhan keluarga. Dari uji kelayakan tersebut yaitu $\mathrm{RCR}=1,42$ artinya setiap Rp. 1,- biaya yang dikeluarkan pengrajin akan di dapat penerimaan sebesar Rp. 1,4.

\section{KESIMPULAN}

Besarnya biaya yang harus dikeluarkan oleh pengrajin saat melaksanakan produksi kerajinan anyaman kipas rotan pada satu kali produksi tahun 2010 meliputi biaya tetap sebesar Rp. $15.535,49$,- per satu kali produksi dan biaya variabel sebesar Rp. 91.911,32,- Per satu kali produksi. Besarnya penerimaan rata rata yang diperoleh pengrajin responden sebesar Rp. 152.452,83 per satu kali produksi. Besar nilai rata - rata $\mathrm{RCR}=1,42$ yang berarti kerajinan anyaman kipas rotan ini menguntungkan dan layak untuk di usahakan. 
Rawa Sains: Jurnal Sains STIPER Amuntai, Desember 2011, 1(1), 18-23.

Badan Pusat Statistik. 2010. Data Perkembangan Produksi Anyaman Rotan Di Kabupaten Hulu Sungai Utara. Badan Pusat Statistik Kabupaten Hulu Sungai Utara.

Dinas Koperasi Perindustrian dan Perdagangan. 2009. Data Potensi Komoditi Unggulan atau Jumlah Industri Kecil Daerah di Kabupaten Hulu Sungai Utara. Dinas Koperasi Perindustrian dan Perdagangan Kabupaten Hulu Sungai Utara. Amuntai.

Kantor Camat Haur Gading. 2009. Data Pengrajin Anyaman Rotan dan
Bambu di Kecamatan Haur Gading. Kantor Camat Haur Gading Kabupaten Hulu Sungai Utara.

Mubyarto. 1997. Pengantar Ekonomi Pertanian. LP3ES. Jakarta.

Tim Penyusun. 2010. Data Perkembangan Hasil Anyaman Rotan di Desa Sungai Limas. Masyarakat Desa Sungai Limas Kecamatan Haur Gading Kabupaten Hulu Sungai Utara.

Setiawan, T. B. 2002. Analisis Pendapatan Usaha Kerajinan Rotan. JIPTUMM. Malang. 